\title{
Technology Acceptance Model (TAM) of Statistical Package for the Social Sciences (SPSS) Applications
}

\author{
Echo Perdana Kusumah \\ Department of Management, Faculty of Economic, University of Bangka Belitung \\ echo_perdana@ubb.ac.id
}

\begin{abstract}
Department of Management, Faculty of Economics, University of Bangka Belitung has been using SPSS application in the implementation of teaching management subjects, to improve productivity of lecturers work by automating work in the form of SPSS applications. SPSS application aims to provide convenience and acceleration in the process of completion research. This study aims to find out how the user's perception of usefulness and ease of use of SPSS applications. Respondents in this study amounted to 100 students majoring in management. Method of collecting data using electronic questionnaire (google form), measuring tool with 5point Likert scale, in the validity and reliability test as well analyzed using descriptive analysis by finding the mean value of each item statement. The research model uses Technology Acceptance Model (TAM) with two the main constants are perceived usefulness and perceived ease of use. The results of the discussion show the user perception of the benefits of SPSS application on average overall get the value of Mean with a score of 4.08 and the ease of use SPSS application on average the overall value of Mean score 4.10, so it can be concluded that the respondents get good benefits in using SPSS applications.
\end{abstract}

Keywords: Perception, SPSS Application, Technology Acceptance Model

\section{Pendahuluan}

Aplikasi SPSS (Statistical Package for the Social Sciences) di lingkungan Jurusan Manajemen, Fakultas Ekonomi, Universitas Bangka Belitung sudah menjadi kebutuhan mutlak yang bertujuan untuk mencapai efisiensi dan efektivitas dalam memberikan pelayanan pada mahasiswa. Aplikasi SPSS yang ada dibuat berdasarkan mekanisme yang panjang, melalui berbagai proses kajian dan penyesuaian sehingga menjadi aplikasi yang comfortable, compatible, and user friendly. Aplikasi SPSS bukan hanya sebagai aplikasi pelengkap pengajaran praktikum tetapi aplikasi ini juga dilengkapi dengan fitur-fitur penelitian yang dibutuhkan. Seiring perkembangannya, melalui berbagai proses penyesuaian, saat ini Aplikasi SPSS yang diproduksi oleh perusahaan IBM sudah dimodifikasi dan mencapai bentuk aplikasi terkini yaitu SPSS versi 24. Aplikasi SPSS dirasa oleh Jurusan Manajemen, Fakultas Ekonomi, Universitas Bangka Belitung sangat relevan dan merupakan solusi yang tepat dalam rangka menyeimbangkan peran dan fungsi perguruan tinggi dengan kebutuhan percepatan peningkatan pelayanan terhadap mahasiswa. Walaupun demikian masih ada mahasiswa di lingkungan Jurusan Manajemen, Fakultas Ekonomi, Universitas Bangka Belitung yang belum optimal memanfaatkan aplikasi ini untuk mendukung pekerjaannya. Kurangnya kemampuan dan pemahaman dalam mengoperasikan perangkat komputer baik itu perangkat keras dan perangkat lunak merupakan 
salah satu penyebab belum optimalnya penggunaan aplikasi berbasis teknologi (Sari \& Witono, 2014; Andriani, 2010; Wedhasmara, 2014).

Model penerimaan teknologi atau Technology Acceptance Model (TAM) yang dikembangkan oleh Davis F.D pada tahun 1986 (Kusumah, 2009), digunakan dalam penelitian ini untuk mengukur persepsi penerimaan pengguna terhadap teknologi informasi dengan menggunakan dua konstruk utama TAM yaitu persepsi pengguna terhadap kemanfaatan/kegunaan (Perceived Usefulness) dan persepsi pengguna terhadap kemudahan penggunaan (Perceived Ease Of Use). TAM (Technology Acceptance Model) yang dikembangkan dari teori psikologis menjelaskan perilaku pengguna teknologi informasi, yaitu berlandaskan pada kepercayaan, sikap, intensitas dan hubungan perilaku pengguna (Kusumah, 2009). Tujuan model ini untuk menjelaskan tentang persepsi pengguna terhadap manfaat dan kemudahan dalam penggunaan teknologi informasi itu sendiri. Salahsatu keberhasilan dari penerapan aplikasi SPSS adalah kesiapan sumber daya manusia. Sumber daya manusia khususnya adalah pengguna dari aplikasi tersebut. Tahap pertama dari keberhasilan penerapan aplikasi SPSS adalah kemauan pengguna untuk menerima aplikasi SPSS tersebut, apakah aplikasi SPSS itu bermanfaat dan memberikan kemudahan bagi pengguna.

\section{Kajian Pustaka}

\section{Persepsi}

Persepsi adalah tanggapan untuk penerimaan langsung dari suatu serapan atau proses seseorang untuk mengetahui beberapa hal melalui panca indranya (Kamus Besar Bahasa Indonesia, 2017). Sedangkan, menurut Walgito (2010), persepsi merupakan suatu proses penginderaan, yaitu merupakan proses diterimanya stimulus oleh individu melalui alat indera atau juga disebut proses sensoris. Namun proses itu tidak berhenti begitu saja, melainkan stimulus tersebut diteruskan dan proses selanjutnya merupakan proses persepsi. Oleh Karena itu proses persepsi tidak bisa lepas dari proses penginderaan yang merupakan proses pendahulu dari proses persepsi. Menurut Kotler (2013), persepsi adalah dimana kita memilih, mengatur, dan menerjemahkan masukan informasi untuk menciptakan gambaran dunia yangberarti. Dari beberapa pengertian persepsi sebelumnya, dapat diambil kesimpulan bahwa persepsi pengguna adalah suatu pandangan proses sebagai pengorganisasian, penerimaan, dan penginterpretasi pengguna yang dalam penelitian disini adalah mahasiswa.

\section{Aplikasi SPSS}

Menurut Technopedia (2017), Aplikasi SPSS (Statistical Package for the Social Sciences) adalah paket perangkat lunak yang digunakan dalam analisis statistik data. Ini dikembangkan oleh SPSS Inc. dan diakuisisi oleh IBM pada tahun 2009. Pada tahun 2014, perangkat lunak tersebut secara resmi berganti nama menjadi Statistik SPSS IBM. Perangkat lunak ini pada awalnya ditujukan untuk ilmu sosial, namun telah populer di bidang lain seperti ilmu kesehatan dan terutama di bidang pemasaran, riset pasar dan data mining. SPSS adalah program yang banyak digunakan untuk analisis statistik dalam ilmu sosial, khususnya di bidang pendidikan dan penelitian. Namun, karena potensinya, ini juga banyak digunakan oleh periset pasar, periset perawatan kesehatan, organisasi survei, pemerintah dan, terutama, mahasiswa dan dosen ilmu sosial. Sedangkan menurut Mathew Chandler (2017) dari University of Windsor, selain dari analisis statistik, perangkat lunak SPSS juga dilengkapi dengan pengelolaan data, yang memungkinkan pengguna untuk melakukan pemilihan kasus, membuat data yang diturunkan dan melakukan 
pembentuk ulang file. Fitur lainnya adalah dokumentasi data, yang menyimpan kamus metadata beserta datafile. Dari penjelasan diatas, aplikasi SPSS bagi mahasiswa Jurusan Manajemen, Fakultas Ekonomi, Universitas Bangka Belitung diharapkan dapat menganalisis dan menyajikan data-data hasil penelitian mereka secara deskriptif denganlebih mudah dan informatif.

\section{Technology Acceptance Model (TAM)}

Technology Acceptance Model (TAM) merupakan teori penerimaan teknologi yang dikembangkan oleh Davis pada tahun 1986 (Kusumah, 2009; Gefen \& Larsen; 2017; Wu \& Chen, 2017). Model TAM diadopsi dari model Theory of Reasoned Action (TRA), yaitu teori tindakan yang beralasan yang dikembangkan oleh Fishben dan Ajzen tahun 1975 (Jokar, Noorhosseini, Allahyari \& Damalas, 2017; Xu, Thong \& Tam, 2017) dengan satu premis bahwa reaksi dan persepsi seseorang terhadap sesuatu hal, akan menentukan sikap dan perilaku orang tersebut. Teori ini membuat model perilaku seseorang sebagai suatu fungsi dari tujuan perilaku. TAM secara lebih terperinci menjelaskan penerimaan teknologi informasi dengan dimensidimensi tertentu yang dapat mempengaruhi dengan mudah diterimanya teknologi informasi dalam hal ini adalah aplikasi SPSS oleh pengguna. Persepsi dari tiap-tiap perilaku pengguna ditempatkan dalam model TAM ini dengan dua pernyataan yaitu kemanfaatan dan kemudahan penggunaan. Kesimpulannya adalah TAM dapat menjelaskan bahwa persepsi mahasiswa terhadap manfaat dan kemudahan akan menentukan penerimaan aplikasi SPSS.

\section{Metode Penelitian}

\section{Tempat, Waktu dan Jenis Data Penelitian}

Penelitian ini dilaksanakan di lingkungan Jurusan Manajemen, Fakultas Ekonomi, Universitas Bangka Belitung, Indonesia, selama dua bulan, yaitu pada bulan November dan Desember 2017. Jenis data dalam penelitian ini menggunakan jenis data primer yaitu data didapatkan langsung dari sumbernya dengan menyebarkan kuesioner elektronik (Google Form). Pengguna sistem informasi yang dimaksud dalam penelitian ini adalah Mahasiswa semester akhir yang telah menggunakan aplikasi SPSS yang berjumlah 100 orang.

\section{Instrumen Penelitian}

Instrumen penelitian merupakan alat bantu pada waktu penelitian menggunakan pengumpulan data (Creswell \& Creswell, 2017; Beins, 2017). Instrumen penelitian yang dipakai dalam penelitian ini adalah kuesioner atau angket. Kuesioner ini terdiri dari dua bagian, yaitu: bagian pertama berisi tentang identitas responden, bagian kedua berisi sejumlah pertanyaan dan pernyataan yang telah terstruktur dengan menggunakan skala likert mengenai persepsi pengguna terhadap kemanfaatan (Perceived Ease Of Use) aplikasi SPSS dan persepsi pengguna terhadap kemudahan penggunaan aplikasi SPSS.

Tabel 1. Kuesioner Perceived Ease Of Use

\begin{tabular}{|c|l|c|c|c|c|c|}
\hline \multirow{2}{*}{ No } & \multicolumn{2}{|c|}{ Pertanyan } & \multicolumn{5}{|c|}{ Likert Scale } \\
\cline { 3 - 7 } & & STS & TS & N & S & SS \\
\hline 1 & Aplikasi SPSS mempermudah tugas saya & & & & & \\
\hline 2 & $\begin{array}{l}\text { Aplikasi SPSS sangat mudah diakses dari } \\
\text { semua spesifikasi komputer }\end{array}$ & & & & \\
\hline 3 & Input data dapat dilakukan dengan mudah & & & & & \\
\hline 4 & Aplikasi SPSS yang ada mudah digunakan & & & & & \\
\hline
\end{tabular}


IJBE: Integrated Journal of Business and Economics e-ISSN: 2549-3280

\begin{tabular}{|c|l|l|l|l|l|}
\hline 5 & $\begin{array}{l}\text { Aplikasi SPSS yang disajikan jelas untuk di } \\
\text { pelajari dan dimengerti }\end{array}$ & & & & \\
\hline 6 & $\begin{array}{l}\text { Tata letak tampilan/display mudah dikenali } \\
\text { /dilihat }\end{array}$ & & & & \\
\hline
\end{tabular}

Tabel 2. Kuesioner Perceived Usefulness

\begin{tabular}{|c|c|c|c|c|c|c|}
\hline \multirow{2}{*}{ No } & \multirow{2}{*}{ Pertanyan } & \multicolumn{5}{|c|}{ Likert Scale } \\
\hline & & STS & TS & $\mathrm{N}$ & $S$ & SS \\
\hline 1 & $\begin{array}{l}\text { Dengan menggunakan Aplikasi SPSS, } \\
\text { mempercepat penyelesaian tugas-tugas saya }\end{array}$ & & & & & \\
\hline 2 & $\begin{array}{l}\text { Dengan menggunakan Aplikasi SPSS, } \\
\text { meringankan pekeriaan saya (tugas dan uijan) }\end{array}$ & & & & & \\
\hline 3 & $\begin{array}{l}\text { Dengan menggunakan Aplikasi SPSS, } \\
\text { membuat pekerjaan (tugas dan ujian) saya } \\
\text { lebih mudah }\end{array}$ & & & & & \\
\hline 4 & $\begin{array}{l}\text { Dengan menggunakan Aplikasi SPSS, Data } \\
\text { dapat diakses oleh bagian yang membutuhkan } \\
\text { seperti teman dan dosen saya. }\end{array}$ & & & & & \\
\hline 5 & $\begin{array}{l}\text { Menurut saya, aplikasi SPSS berguna dalam } \\
\text { pekerjaan saya (tugas dan ujian) }\end{array}$ & & & & & \\
\hline
\end{tabular}

\section{Uji Instrumen \\ Uji Validitas}

Validitas adalah ukuran yang menunjukkan tingkat kevalidan atau kesahihan suatu instrumen. Instrumen dikatakan valid apabila Instrumen tersebut dapat melakukan apa yang seharusnya dilakukan dan mengukur apa yang harus diukur (Sugiyono, 2016; Ghozali, 2016). Uji validitas digunakan untuk mengetahui tingkat kesahihan setiap butir pertanyaan dalam angket atau kuesioner. Kuesioner yang baik harus dapat berfungsi sebagai alat pengumpul data yang tepat dan akurat. Uji validitas dilakukan terhadap seluruh butir pertanyaan dalam instrumen, yaitu dengan cara mengkorelasikan skor setiap butir dengan skor total melalui teknik Pearson Correlation $(\mathrm{Pc})$. Nilai Pc yang didapati akan dibandingkan dengan nilai r-tabel, dimana jika nilai Pc lebih besar dari r-tabel $(P c>r$-table) maka butir pertanyaan tersebut dianggap valid (Kusumah, 2016).

\section{Uji Reliabilitas}

Suatu alat pengukuran dikatakan realiabel apabila mendapatkan hasil yang tetap sama dari gejala pengukuran yang tidak berubah yang dilakukan pada waktu yang berbeda. Instrumen dikatakan reliable apabila dipergunakan beberapa kali untuk mengukur objek yang sama dalam waktu yang berbeda akan menghasilkan data yang sama. Reliabilitas adalah indeks yang menunjukkan sejauhmana suatu alat pengukur dapat dipercaya atau dapat diandalkan (Ghozali, 2016; Ferdinand, 2014). Dengan kata lain, realibilitas menunjukkan konsistensi dan stabilitas dari suatu skala pengukuran dengan menggunakan nilai croncbach alpha pada hasil analisis (Kusumah, 2016).

\section{Analisis Data Analisis Deskriptif}


Analisis deskriptif merupakan analisa terhadap konstruk instrumen penelitian dimana analisa dilakukan berdasarkan dari hasil pernyataan responden pada masing-masing pertanyaan disetiap indikator. Analisis deskriptif ini dikemukakan cara-cara penyajian data dalam tabel maupun diagram yaitu penentuan rata-rata (mean). Arti dari mean atau disebut mean aritmatika adalah salah satu tipe dari rata-rata (average). Menurut Sugiyono (2016), analisa dilakukan dengan menggunakan nilai mean yaitu menentukan nilai besarnya kelas sebagai berikut:

$$
\begin{gathered}
\text { Nilai maksimum }=5 ; \text { Nilai Minimum }=1 \\
\text { Rentang Skor }=(5-1) / 5=0,8 \\
\text { Kategori : } \\
-1,00 \text { s.d } 1,80=\text { sangat rendah/sangat buruk } \\
-1,81 \text { s.d } 2,60=\text { rendah/buruk } \\
-2,61 \text { s.d } 3,40=\text { sedang/cukup } \\
-3,41 \text { s.d } 4,20=\text { baik/tinggi } \\
-4,21 \text { s.d } 5,00=\text { sangat baik/sangat tinggi }
\end{gathered}
$$

Setelah mendapatkan hasil perhitungan statistika maka dilakukan penafsiran sesuai dengan kondisi yang ada. Untuk memudahkan penghitungan tersebut peneliti menggunakan aplikasi SPSS Versi 22.0 untuk sistem operasi Window.

\section{Pembahasan Hasil}

\section{Pengujian Kuesioner}

\section{Uji Validitas Perceived Usefulness (PU)}

Hasil uji validitas yang telah dilakukan terhadap perceived usefulness (PU) menunjukkan bahwa seluruh butir pernyataan (5 butir) yang ada memiliki skor validitas di atas r-tabel $(0,197)$, sehingga dapat dinyatakan seluruh butir pertanyaan tersebut valid. Batasan nilai r-tabel dengan $\mathrm{n}$ $=100(\mathrm{df}=\mathrm{n}-2)$ maka di dapat nilai r-tabel sebesar 0,197 artinya jika nilai Pearson Correlation lebih dari batasan r-tabel yang ditentukan maka butir dianggap valid, sedang jika kurang dari batasan r-tabel yang ditentukan maka butir dianggap tidak valid.

Hasil uji validitas terhadap pernyataan butir 1 (X2.1) sampai dengan butir 5 (X2.5) dalam dimensi perceived usefulness (PU) skor lengkapnya tersaji pada Tabel 3 berikut :

\section{Tabel 3. Nilai Validitas Perceived Usefulness}

\begin{tabular}{|ll|r|r|r|r|r|r|}
\hline & & \multicolumn{1}{|c|}{ Correlations } \\
\hline X2.1 & Xearson Correlation & 1 &, $778^{* *}$ &, $791^{* *}$ &, $620^{* *}$ &, $614^{* *}$ &, $874^{* *}$ \\
& Sig. (2-tailed) & &, 000 &, 000 &, 000 &, 000 &, 000 \\
& $\mathrm{~N}$ & 100 & 100 & 100 & 100 & 100 & 100 \\
\hline X2.2 & Pearson Correlation &, $778^{* *}$ & 1 &, $892^{* *}$ &, $626^{* *}$ &, $696^{* *}$ &, $927^{* *}$ \\
& Sig. (2-tailed) &, 000 & &, 000 &, 000 &, 000 &, 000 \\
& N & 100 & 100 & 100 & 100 & 100 & 100 \\
\hline X2.3 & Pearson Correlation &, $791^{* *}$ &, $892^{* *}$ & 1 &, $567^{* *}$ &, $673^{* *}$ &, $913^{* *}$
\end{tabular}


IJBE: Integrated Journal of Business and Economics e-ISSN: 2549-3280

\begin{tabular}{|ll|r|r|r|r|r|r|} 
& Sig. (2-tailed) &, 000 &, 000 & &, 000 &, 000 &, 000 \\
& $\mathrm{~N}$ & 100 & 100 & 100 & 100 & 100 & 100 \\
\hline X2.4 & Pearson Correlation &, $620^{* *}$ &, $626^{*}$ &, $567^{*}$ & 1 &, $665^{* *}$ &, $789^{* *}$ \\
& Sig. (2-tailed) &, 000 &, 000 &, 000 & &, 000 &, 000 \\
& $\mathrm{~N}$ & 100 & 100 & 100 & 100 & 100 & 100 \\
\hline X2.5 & Pearson Correlation &, $614^{* *}$ &, $696^{* *}$ &, $673^{* *}$ &, $665^{* *}$ & 1 &, $836^{* *}$ \\
& Sig. (2-tailed) &, 000 &, 000 &, 000 &, 000 & &, 000 \\
& N & 100 & 100 & 100 & 100 & 100 & 100 \\
\hline PU & Pearson Correlation &, $874^{* *}$ &, $927^{* *}$ &, $913^{* *}$ &, $789^{* *}$ &, $836^{* *}$ & 1 \\
& Sig. (2-tailed) &, 000 &, 000 &, 000 &, 000 &, 000 & 100 \\
& N & 100 & 100 & 100 & 100 & 100 & 100 \\
\hline
\end{tabular}

**. Correlation is significant at the 0.01 level (2-tailed).

Dari data output Tabel 1 dapat dilihat bahwa nilai Pearson Correlation dari butir 1 sampai butir 5 berada di atas r-tabel 0,197 dan memiliki tanda bintang dua, artinya hal ini menunjukan bahwa butir tersebut valid dan nilai ini signifikan pada tingkat signifikansi 0,00 .

\section{Uji Validitas Dimensi Perceived Ease of Use (PEU)}

Hasil uji validitas yang telah dilakukan terhadap perceived Ease of Use (PEU) menunjukkan bahwa seluruh butir pernyataan ( 6 butir) yang ada memiliki skor validitas di atas r-tabel $(0,197)$, sehingga dapat dinyatakan seluruh butir pertanyaan tersebut valid. Batasan nilai r-tabel dengan $\mathrm{n}$ $=100(\mathrm{df}=\mathrm{n}-2)$ maka di dapat nilai r-tabel sebesar 0,197 artinya jika nilai Pearson Correlation lebih dari batasan r-tabel yang ditentukan maka butir dianggap valid, sedang jika kurang dari batasan r-tabel yang ditentukan maka butir dianggap tidak valid.

Hasil uji validitas terhadap pernyataan butir 1 (X1.1) sampai dengan butir 6 (X1.6) dalam dimensi perceived usefulness (PEU) skor lengkapnya tersaji pada Tabel 4 berikut :

Tabel 4. Nilai Validitas Perceived Ease of Use

\begin{tabular}{|c|c|c|c|c|c|c|c|c|}
\hline \multicolumn{9}{|c|}{ Correlations } \\
\hline & & $\mathrm{X} 1.1$ & $\mathrm{X} 1.2$ & $\mathrm{X} 1.3$ & $\times 1.4$ & $\times 1.5$ & $\mathrm{X} 1.6$ & PEU \\
\hline \multirow[t]{3}{*}{$\mathrm{X} 1.1$} & Pearson Correlation & 1 &, $726^{* *}$ &, $374^{* *}$ &, $719^{* *}$ &, $626^{* *}$ &, $601^{* *}$ & ,854 \\
\hline & Sig. (2-tailed) & &, 000 &, 000 &, 000 &, 000 &, 000 & ,000 \\
\hline & $\mathrm{N}$ & 100 & 100 & 100 & 100 & 100 & 100 & 100 \\
\hline \multirow[t]{3}{*}{$\mathrm{X} 1.2$} & Pearson Correlation &, $726^{* *}$ & 1 &, $366^{* *}$ &, $602^{* *}$ &, $579^{* *}$ &, $503^{* *}$ & $807^{* *}$ \\
\hline & Sig. (2-tailed) &, 000 & &, 000 &, 000 &, 000 &, 000 & ,000 \\
\hline & $\mathrm{N}$ & 100 & 100 & 100 & 100 & 100 & 100 & 100 \\
\hline \multirow[t]{3}{*}{$\mathrm{X} 1.3$} & Pearson Correlation &, $374^{\star *}$ &, $366^{* *}$ & 1 &, $546^{* *}$ &, $412^{\star \star}$ &, $422^{* *}$ &, $635^{* *}$ \\
\hline & Sig. (2-tailed) &, 000 &, 000 & &, 000 &, 000 &, 000 &, 000 \\
\hline & $\mathrm{N}$ & 100 & 100 & 100 & 100 & 100 & 100 & 100 \\
\hline
\end{tabular}


IJBE: Integrated Journal of Business and Economics e-ISSN: 2549-3280

\begin{tabular}{|c|c|c|c|c|c|c|c|c|}
\hline \multirow[t]{3}{*}{ X1.4 } & Pearson Correlation & ,719" & ,602" &, 546 & 1 &, $707^{* *}$ &, $566^{* \prime}$ & 864 \\
\hline & Sig. (2-tailed) &, 000 & ,000 &, 000 & &, 000 &, 000 &, 000 \\
\hline & $\mathrm{N}$ & 100 & 100 & 100 & 100 & 100 & 100 & 100 \\
\hline \multirow[t]{3}{*}{ X1.5 } & Pearson Correlation &, $626^{* *}$ &, $579^{* *}$ & , 412** &, $707 *$ & 1 & ,622" & $831 *$ \\
\hline & Sig. (2-tailed) &, 000 & ,000 & 000 &, 000 & &, 000 &, 000 \\
\hline & $\mathrm{N}$ & 100 & 100 & 100 & 100 & 100 & 100 & 100 \\
\hline \multirow[t]{3}{*}{ X1.6 } & Pearson Correlation &, $601^{* *}$ &, $503^{* *}$ & ,422 &, $566 *$ & ,622** & 1 &, 776 \\
\hline & Sig. (2-tailed) &, 000 & 000 & ,000 &, 000 &, 000 & &, 000 \\
\hline & $\mathrm{N}$ & 100 & 100 & 100 & 100 & 100 & 100 & 100 \\
\hline \multirow[t]{3}{*}{ PEU } & Pearson Correlation &, $854^{* *}$ &, $807^{* *}$ &, $635^{*}$ & 864 & $831^{* *}$ &, $776^{* *}$ & 1 \\
\hline & Sig. (2-tailed) &, 000 & 000 & ,000 &, 000 &, 000 &, 000 & \\
\hline & $\mathrm{N}$ & 100 & 100 & 100 & 100 & 100 & 100 & 100 \\
\hline
\end{tabular}

**. Correlation is significant at the 0.01 level (2-tailed).

Dari data output Tabel 4 dapat dilihat bahwa nilai Pearson Correlation dari butir 1 sampai butir 6 berada di atas r-tabel 0,197 dan memiliki tanda bintang dua, artinya hal ini menunjukan bahwa butir tersebut valid dan nilai ini signifikan pada tingkat signifikansi 0,00 .

\section{Uji Reliabilitas}

Uji reliabilitas digunakan untuk membuktikan bahwa butir-butir pernyataan dalam kuesioner konsisten atau tidak. Apabila nilai Cronbach Alpha > r-tabel maka butir-butir pernyataan dalam kuesioner tersebut dapat dipercaya atau reliabel. Hasil uji reliabilitas dari kedua secara rinci tersaji pada Tabel 5 berikut:

Tabel 5. Hasil Uji Reliabilitas Perceived Ease of Use dan Perceived Usefulness

Reliability Statistics

\begin{tabular}{|r|r|}
\hline \multicolumn{1}{|c|}{$\begin{array}{l}\text { Cronbach's } \\
\text { Alpha }\end{array}$} & N of ltems \\
\hline, 884 & 6 \\
\hline
\end{tabular}

\begin{tabular}{|c|c|c|c|c|}
\hline \multicolumn{5}{|c|}{ Item-Total Statistics } \\
\hline & $\begin{array}{l}\text { Scale Mean if } \\
\text { Item Deleted }\end{array}$ & $\begin{array}{l}\text { Scale Variance } \\
\text { if Item Deleted }\end{array}$ & $\begin{array}{l}\text { Corrected Item- } \\
\text { Total Correlation }\end{array}$ & $\begin{array}{c}\text { Cronbach's } \\
\text { Alpha if Item } \\
\text { Deleted }\end{array}$ \\
\hline $\mathrm{X} 1.1$ & 20,41 & 11,275 & ,778 & ,850 \\
\hline $\mathrm{X} 1.2$ & 20,50 & 11,081 & ,694 & ,865 \\
\hline $\mathrm{X} 1.3$ & 20,56 & 13,178 &, 503 & ,891 \\
\hline $\mathrm{X} 1.4$ & 20,59 & 11,456 &, 797 & ,848 \\
\hline X1.5 & 20,61 & 11,311 &, 740 & ,856 \\
\hline X1.6 & 20,43 & 11,965 & ,672 & ,867 \\
\hline
\end{tabular}


IJBE: Integrated Journal of Business and Economics e-ISSN: 2549-3280

Reliability Statistics

\begin{tabular}{|c|c|}
\hline $\begin{array}{c}\text { Cronbach's } \\
\text { Alpha }\end{array}$ & $\mathrm{N}$ of Items \\
\hline 918, & 5 \\
\hline
\end{tabular}

Item-Total Statistics

\begin{tabular}{|l|r|r|r|r|}
\hline & Scale Mean if & & & \multicolumn{2}{c|}{$\begin{array}{c}\text { Cronbach's } \\
\text { Scale Variance } \\
\text { Item Deleted }\end{array}$} & $\begin{array}{r}\text { Corrected Item- } \\
\text { if Item Deleted }\end{array}$ & $\begin{array}{c}\text { Alpha if Item } \\
\text { Total Correlation }\end{array}$ \\
\hline X2.1 & 16,22 & 8,678 &, 806 &, 898 \\
X2.2 & 16,40 & 7,859 &, 876 &, 882 \\
X2.3 & 16,46 & 7,685 &, 849 &, 888 \\
X2.4 & 16,33 & 9,213 &, 686 &, 920 \\
X2.5 & 16,19 & 8,782 &, 746 &, 909 \\
\hline
\end{tabular}

Dari data output Tabel 5 dapat dilihat bahwa nilai Cronbach's Alpha dari butir pertanyaan X1.1 sampai butir X2.5 memiliki nilai diatas nilai r tabel sebesar 0,197, artinya hal ini menunjukan bahwa butir pertanyaan yang ada tersebut dapat dipercaya atau reliabel.

\section{Analisis Deskriptif}

Persepsi Pengguna Terhadap Kemudahan Penggunaan Aplikasi SPSS

Hasil analisis deskriptif data skor perceived ease of use disajikan pada Tabel 6 berikut:

Tabel 6. Skor Perceived Ease of Use

\begin{tabular}{|c|l|c|c|c|c|}
\hline No & \multicolumn{1}{|c|}{ Pertanyan } & N & Min & Max & Mean \\
\hline 1 & Aplikasi SPSS mempermudah tugas saya & 100 & 1 & 5 & 4,21 \\
\hline 2 & $\begin{array}{l}\text { Aplikasi SPSS sangat mudah diakses dari semua } \\
\text { spesifikasi komputer }\end{array}$ & 100 & 1 & 5 & 4,12 \\
\hline 3 & Input data dapat dilakukan dengan mudah & 100 & 1 & 5 & 4,06 \\
\hline 4 & Aplikasi SPSS yang ada mudah digunakan & 100 & 1 & 5 & 4,03 \\
\hline 5 & $\begin{array}{l}\text { Aplikasi SPSS yang disajikan jelas untuk di } \\
\text { pelajari dan dimengerti }\end{array}$ & 100 & 2 & 5 & 4,01 \\
\hline 6 & $\begin{array}{l}\text { Tata letak tampilan/display mudah dikenali } \\
\text { /dilihat }\end{array}$ & 100 & 2 & 5 & 4,19 \\
\hline & Rata-rata & & & & 4,10 \\
\hline
\end{tabular}

Berdasarkan Tabel 6 dapat dilihat bahwa untuk pernyataan butir 1 sampai dengan butir 6 untuk persepsi pengguna terhadap kemudahan penggunaan aplikasi SPSS (perceived ease of use) secara rata-rata keseluruhan nilai Mean mendapatkan skor 4,10, dengan Jumlah N Valid sebesar 100 responden. Persepsi pengguna terhadap kemudahan penggunaan aplikasi SPSS dapat dinyatakan baik atau tinggi, ini menunjukan responden mempunyai persepsi bahwa aplikasi SPSS mudah untuk digunakan. 
IJBE: Integrated Journal of Business and Economics

e-ISSN: 2549-3280

\section{Persepsi Pengguna Terhadap Kemanfaatan Aplikasi SPSS}

Hasil analisis deskriptif data skor Perceived Usefulness disajikan pada Tabel 7 berikut:

Tabel 7. Skor Perceived Usefulness

\begin{tabular}{|c|l|c|c|c|c|}
\hline No & \multicolumn{1}{|c|}{ Pertanyan } & N & Min & Max & Mean \\
\hline 1 & $\begin{array}{l}\text { Dengan menggunakan Aplikasi SPSS, } \\
\text { mempercepat penyelesaian tugas-tugas saya }\end{array}$ & 100 & 2 & 5 & 4,18 \\
\hline 2 & $\begin{array}{l}\text { Dengan menggunakan Aplikasi SPSS, } \\
\text { meringankan pekerjaan saya (tugas dan ujian) }\end{array}$ & 100 & 1 & 5 & 4,00 \\
\hline 3 & $\begin{array}{l}\text { Dengan menggunakan Aplikasi SPSS, } \\
\text { membuat pekerjaan (tugas dan ujian) saya } \\
\text { lebih mudah }\end{array}$ & 100 & 1 & 5 & 3,94 \\
\hline 4 & $\begin{array}{l}\text { Dengan menggunakan Aplikasi SPSS, Data } \\
\text { dapat diakses oleh bagian yang membutuhkan } \\
\text { seperti teman dan dosen saya. }\end{array}$ & 100 & 1 & 5 & 4,07 \\
\hline 5 & $\begin{array}{l}\text { Menurut saya, aplikasi SPSS berguna dalam } \\
\text { pekerjaan saya (tugas dan ujian) } \\
\text { Rata-rata }\end{array}$ & 100 & 1 & 5 & 4,21 \\
\hline & & & & & 4,08 \\
\hline
\end{tabular}

Berdasarkan Tabel 7 dapat dilihat bahwa untuk pernyataan butir 1 sampai dengan butir 5 untuk persepsi pengguna terhadap kemanfaatan aplikasi SPSS (perceived usefulness) secara rata-rata keseluruhan mendapatkan nilai Mean dengan skor 4,08, dengan Jumlah N Valid sebesar 100 responden. Hal ini menunjukan bahwa secara keseluruhan persepsi pengguna terhadap kemanfaatan (Perceived Usefulness) menggunakan aplikasi SPSS baik atau menerima aplikasi SPSS yang digunakan jurusan Manajemen FE-UBB, sehingga dapat disimpulkan bahwa responden mendapatkan manfaat yang baik dalam menggunakan aplikasi SPSS.

\section{KESIMPULAN}

Berdasarkan hasil analisis data terhadap 100 responden di Jurusan Manajemen, Fakultas Ekonomi, Universitas Bangka Belitung tentang persepsi pengguna terhadap kemanfaatan dan persepsi kemudahan penggunaan (TAM) aplikasi SPSS, maka dapat disimpulkan bahwa:

1. Persepsi pengguna terhadap kemanfaatan aplikasi Sistem Informasi Baru (Perceived Usefulness) sudah baik, hal ini berdasarkan pada rata-rata nilai mean mendapatkan skor 4,10 ini berarti bahwa aplikasi SPSS yang telah digunakan dalam proses pengajaran bermanfaat dan dapat diterima oleh pengguna, dalam hal ini yaitu mahasiswa Jurusan Manajemen, Fakultas Ekonomi, Universitas Bangka Belitung.

2. Persepsi pengguna terhadap kemudahan penggunaan aplikasi SPSS (Perceived Ease Of Use) sudah baik, hal ini berdasarkan pada rata-rata nilai mean mendapatkan skor 4,08, hal ini menunjukan bahwa aplikasi SPSS mudah digunakan, ini berarti aplikasi SPSS memberikan kemudahan dalam proses pembelajaran oleh mahasiswa Jurusan Manajemen, Fakultas Ekonomi, Universitas Bangka Belitung. 
IJBE: Integrated Journal of Business and Economics

e-ISSN: 2549-3280

\section{Referensi}

Andriani, W. (2010). Pengaruh Kapasitas Sumber Daya Manusia dan Pemanfaatan Teknologi Informasi Terhadap Keterandalan dan Ketepatwaktuan Laporan Keuangan Pemerintah Daerah (Studi pada Pemerintah Daerah Kab. Pesisir Selatan). Jurnal Akuntansi \& Manajemen, 5(1), 69-80.

Beins, B. C. (2017). Research method: A tool for life. Cambridge University Press.

Chandler, M. (2017). What is SPSS? Retrieved December 11, 2017, from http://www.uwindsor.ca/its/81/ statistical-software-support-page

Creswell, J. W., \& Creswell, J. D. (2017). Research design: Qualitative, quantitative, and mixed methods approaches. Sage publications.

Ferdinand, Augusty. (2014). Metode Penelitian Manajemen. Semarang: Badan Penerbit Universitas Diponegoro.

Gefen, D., \& Larsen, K. (2017). Controlling for Lexical Closeness in Survey Research: A Demonstration on the Technology Acceptance Model. Journal of the Association for Information Systems, 18(10), 727-757.

Ghozali, Imam. (2016). Aplikasi Analisis Multivariate Dengan Program IBM SPSS 23. Semarang: Badan Penerbit Universitas Diponegoro

Jokar, N. K., Noorhosseini, S. A., Allahyari, M. S., \& Damalas, C. A. (2017). Consumers' acceptance of medicinal herbs: an application of the technology acceptance model (TAM). Journal of Ethnopharmacology.

Kusumah, E. P. (2016). Olah Data Skripsi Dengan SPSS 22. Pangkalpinang, Bangka Belitung: LABKOM FE-UBB. doi:https://doi.org/10.5281/zenodo.1143815

Kusumah, E. P. (2009). Ultilization of On-line Application Among International Students for Entry Into Universiti Utara Malaysia (UUM) (Doctoral dissertation, Universiti Utara Malaysia).

Sari, S. P., \& Witono, B. (2014). Keterandalan dan ketepatwaktuan pelaporan keuangan daerah ditinjau dari sumber daya manusia, pengendalian internal dan pemanfaatan teknologi informasi.

Sugiyono. (2016). Metodologi Penelitian Kuantitatif, Kualitatif, dan R\&D. Bandung: CV Alfabeta.

Technopedia. (n.d.). What is the Statistical Package for the Social Sciences (SPSS)? - Definition from Techopedia. Retrieved December 11, 2017, from https://www.techopedia.com/definition/12401/ statistical-package-for-the-social-sciences-spss

Wedhasmara, A. (2014). Langkah-langkah perencanaan strategis sistem informasi dengan menggunakan metode Ward and Peppard. Jurnal Sistem Informasi, 1(1).

Wu, B., \& Chen, X. (2017). Continuance intention to use MOOCs: Integrating the technology acceptance model (TAM) and task technology fit (TTF) model. Computers in Human Behavior, 67, 221-232. 
IJBE: Integrated Journal of Business and Economics e-ISSN: 2549-3280

Xu, X., Thong, J. Y., \& Tam, K. Y. (2017). Winning Back Technology Disadopters: Testing a Technology Readoption Model in the Context of Mobile Internet Services. Journal of Management Information Systems, 34(1), 102-140. 